\title{
Symmetry Analysis in Design of Traditional Malay Paintings through Principle of Repeating Patterns
}

\section{Rushana Sulaiman @ Abd Rahim, Muliyati Mat Alim}

To Link this Article: http://dx.doi.org/10.6007/IJARBSS/v11-i9/11072

DOI:10.6007/IJARBSS/v11-i9/11072

Received: 06 July 2021, Revised: 01 August 2021, Accepted: 28 August 2021

Published Online: 14 September 2021

In-Text Citation: (Rahim \& Alim, 2021)

To Cite this Article: Rahim, R. S. @ A., \& Alim, M. M. (2021). Symmetry Analysis in Design of Traditional Malay Paintings through Principle of Repeating Patterns. International Journal of Academic Research in Business and Social Sciences, 11(9), 830-841.

\section{Copyright: (c) 2021 The Author(s)}

Published by Human Resource Management Academic Research Society (www.hrmars.com)

This article is published under the Creative Commons Attribution (CC BY 4.0) license. Anyone may reproduce, distribute, translate and create derivative works of this article (for both commercial and non-commercial purposes), subject to full attribution to the original publication and authors. The full terms of this license may be seen at: http://creativecommons.org/licences/by/4.0/legalcode

Vol. 11, No. 9, 2021, Pg. 830 - 841

Full Terms \& Conditions of access and use can be found at http://hrmars.com/index.php/pages/detail/publication-ethics 


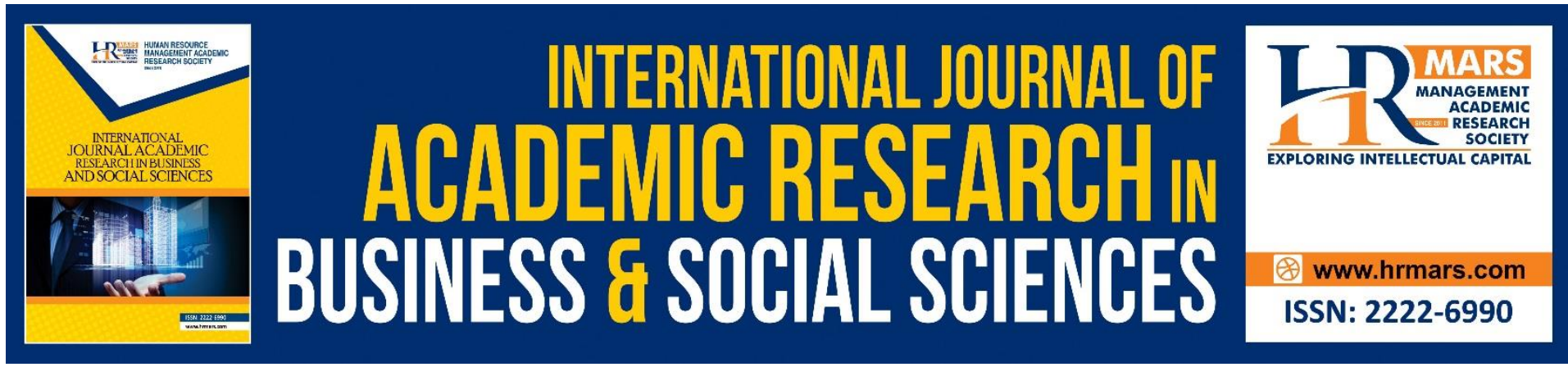

\title{
Symmetry Analysis in Design of Traditional Malay Paintings through Principle of Repeating Patterns
}

\author{
Rushana Sulaiman @ Abd Rahim \\ Faculty of Art \& Design, MARA University of Technology, Malaysia \\ Email: rushana@uitm.edu.my \\ Muliyati Mat Alim \\ Faculty of Arts and Social Science, University Tunku Abdul Rahman,Malaysia \\ Email: muliyati@utar.edu.my
}

\begin{abstract}
This paper aims to examine clearly about the concept of symmetry that exists in paintings through the principle of repetition in art. The main focus of the study is to explore the relationship between the formalistic aspects of art and symmetry through the design of patterns and motifs in The Boundaries' painting by Ruzaika Omar Basaree. He applied the Malay traditional images by using the sculpture's art on wood carving. Symmetry features are examined to classify the combination of repetitive patterns in paintings through series of transformations that include four basics of repetition, namely translation, rotation, reflection and glide reflection. These processes form a structure known as the frieze symmetry group where it covers the seven basics of frieze patterns. Frieze pattern is a pattern on a twodimensional surface that repeats in one direction in a single strip. The written and visual data collection in this study uses descriptive qualitative approach that involves the design of artworks analysis study based on empirically fieldwork for the data obtained. Methods of documentation, visual recording and observation were used to collect information about the paintings studied. The results showed The Boundaries' paintings by Ruzaika Omar Basaree have implemented elements of wood carving in Malay traditional construction that showed symmetrical design. The concepts used in the study underlie the subject, design and aesthetic meaning to classify the pattern of paintings by using symmetrical transformation process. Implications from the study show that paintings that are looked from the view of art appreciation can also be seen through the repetitive geometric system and reflection of images forming interesting combination of compositions, not only can be seen from the formalistic point of view of art alone.
\end{abstract}

Keywords: Art Appreciation, Frieze Pattern, Siri Nurani, Siri Dungun, Symmetry.

Introduction

According Bakar (1995), mathematics is a channel that displays the theory of beauty in Islamic civilization because of its accuracy with the structure of the universe that produces beauty verbally and nature of mathematics. Anuwar (2013) the knowledge of mathematics is used 
by human beings for their daily activities and until today mathematics has become a branch of knowledge that must be studied. Across civilizations and geographies have caused mathematics to be studied by various nations to the point of assimilation between local cultures and mathematics itself.

Abdullah (2015) stated that mathematics is a broad field and geometry is one of the important branches in it. The components of geometry in mathematics including shape, size, direction and movement are known to be one of the basic skills that needed to be mastered in mathematics. Every act in everyday life uses a lot of geometric conceptual terms.

According to Ismail (2004), this world is formed in the language of beautiful geometry. All objects of Divine creation in this universe are in fact geometrically shaped creations that illustrate the reality of the universe. The concept of geometry is widely applied in art; mathematical knowledge not only involves calculations but can also be associated with art. The history of mathematics itself has proven that a combination of motifs or patterns can display the beauty of symmetry.

Symmetrical designs were analysed into three different classes namely points, lines and dimensions. Its use in various art forms in order to classify the repetition of patterns. Through art, a systematic description of symmetry is used to study meaning in the repetition of patterns through context of society. Although humans have natural ability to understand symmetry, it is very important to create a language that studies and understands patterns systematically (Martin, 1982).

Kamal (2016) stated in the context of the Malay-Muslim, understanding of art can be focused into three main properties which are styling, repetition and not individualistic. These are the main concept to meet the demands and needs of Islamic art found in the artwork the shape of symmetry provides exposure to such a broad and interesting principle in the field of mathematics. Symmetry is a symbol of harmony, the ratio of beauty and balance found in the arrangement of pattern design on any repetition of motifs. This process is known as mirroring or symmetrical reflection to reflect the folded image on the line and it will form the same image pattern face to face when inverted as in a mirror along the axis line. Symmetry is a transformation that allows an object or pattern to remain unchanged. According to Weyl (1952), humans used symmetry to understand and produce order, beauty, and perfection.

\section{Repetition of Motifs in Artworks}

Basaree (2018) said that art has different perspectives and approaches in terms of medium and concepts that are highlighted in paintings. Method which combines various techniques, produces a variety of pattern designs from plant motifs and geometry inspired by nature. Emphasis on a more structured arrangement of compositions is preferred in the production of artworks

Plant-shaped and geometric elements are the main subjects of the artwork. Repeated elements play a role in bringing the appearance of nature to produce a balanced and rhythmic image that involves the repetition of shapes. Thus, it creates a spiral pattern form as serenity, which is the essence and true value of beauty. Observation of nature with a combination of colors, lines, shapes and interweaving evokes harmony and peace.

Pattern design that exists from nature as source of inspiration uses repetitive 
processes such as rotating, twisting, reversing, merging, copying and bouncing to make the design more interesting. Plants and geometry are the best examples because they have a variety of natural patterns and shapes. This series of artwork is produced by using three mathematical principles namely translation, rotation and reflection (Basaree, 2018).

The repeated pattern from different patterns and objects but it still shares the principles, symmetry, harmony, structure that is the core to the art of pattern design. The philosophy behind the production of this artwork is to reveal the harmony and structure of the pattern design that can be a source for reminding of the greatness of God. Design adjustment must adhere to the principle of harmony because nothing exists at random. Art is the unification of personal emotions towards environment in which peace and harmony are the subject of our question. The artwork displays two elements of attraction namely:

1. Highlight an alternative approach in dealing with pattern design as suitable alternative approach to talk about art.

2. Apply to the new repeated image an atmosphere of balance in a more controlled arrangement of the composition

\section{Research Methodology}

A qualitative research approach that uses symmetrical analysis case study design, it focuses on the design, pattern variations and motifs in paintings. There are three methods of data collection used such as observation, visual recording and documentation analysis. Data were collected based on empirical fieldwork data obtained while in the field. This study uses the method of symmetric analysis which is part of the mathematical principles by using lines of symmetry to display the pattern of design elements repeatedly. Lines of symmetry also produce similar mirror reflections in terms of lines and planes (Washburn \& Crowe 1988). The symmetric analysis method classifies pattern designs according to the categories found in the transformation process. This includes four basics of repetition namely translation, rotation, reflection and glide reflection. This process forms a structure known as the frieze symmetry group. A frieze pattern is a two-dimensional surface pattern that repeats in one direction that has 7 basic patterns of repetition (Washburn 1988).

\section{Previous Studies}

Abdullah (2016) in his study has classified frieze patterns in Malay songket textile art. It discusses traditional fabric weaving motifs consisting of an arrangement of geometric patterns using translational repetition, reflection and rotation. The analysis uses twodimensional planes (frieze patterns) onto fabric border patterns, fabric legs and fabric heads. This is based on symmetrical geometric patterns on the plane. The findings of the study found that the existence of geometric and symmetrical patterns in songket craft to be a useful contribution to the songket design industry. These analyses of symmetry have been discussed in previous papers such as in Wood Carvings (Silah, 2016), Traditional Malay Utensils (Md Yusoff, 2016), Songket (Nawawi 2014) and Perahu (Rohaizat, 2016). 


\section{Analysis of the Boundaries Artwork}

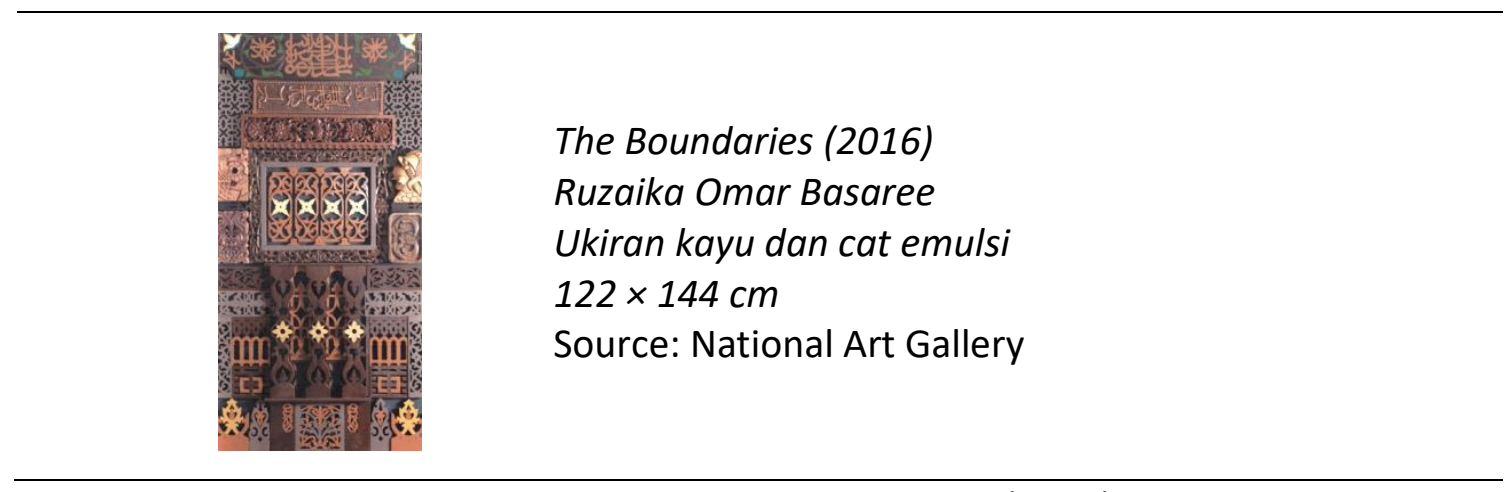

Figure 1. The Boundaries paintings (2016)

Ruzaika Omar Basaree was among the pioneers of women artists who uphold the motif of design patterns Malay wood carving as a major subject in the paintings. The beauty of seni kerawang which became flagship for traditional Malay architecture applied in his work tribute to local sculptor. People have the opportunity to see the production of artworks that showcases the beauty of Islamic art through wood carvings with symmetrical arrangement of patterns and motifs of Malay woodcarving in each of her artwork series. The beauty of philosophy contained in the Malay tradition artworks, not only emphasizes the beauty of the design, but also the philosophy and divinity contained in the essence of a work of art (Basaree, 2018).

The aesthetic value in the motifs and patterns found on the artwork exhibits intellectual and implicit values. Wood carvings that have been formed with motifs of flora, cosmos and geometry are processed in abstract or symbolic forms such as leaves, flowers of flora formed in perforated or embossed perforations. The carved design does not fully resemble the object of flora but is processed into a symbolic form that resembles the object. Among the carvings found in Ruzaika's artworks are perforated carvings, wind lattice, mountain/crown carvings, corner/squirrel carvings, sky -pointing carvings, duck tail carvings, ornate widow wall carvings, kelarai wall carvings, pendulum carvings and gates (Basaree , 2018).

Basaree (2018) stated that the Motif produced is not only seen in the beauty of the artwork alone, but also refers to its functions and uses. There are six principles that form the basic concept of beauty Malay such as smoothness, softness, balance, unity, usefulness and symbols. However, not all principles are highlighted by the author in his artwork where only some are applied which are the principles of subtlety, softness, balance and unity.

Syed Ahmad Jamal, appearance and soul;

Malay art is the transformation from the elements of nature to a form of artwork where it's art and ideas resulting from the appreciation of the creator of an embodiment of the dream, and he reflects a harmony between man and nature.

Traditional sculpture includes the art of pattern design and orderly motifs such as stems, finishes and curves. Motifs used such as living elements, stem and ending flora, stems, 
leaf buds, flowers, fruits, and suckers. Each artwork sculpture gives meaning which is something related to the symbol of natural life. The use of designs and patterns clearly shows the beautiful and exquisite motifs. Motif bamboo shoots and cloud motif contains a strong sense of individuality expressed tenderness and modesty of Malay tradition and the beauty of the carvings, local and over.

Table 1. Geometric design and symmetry of motifs by The Boundaries artwork

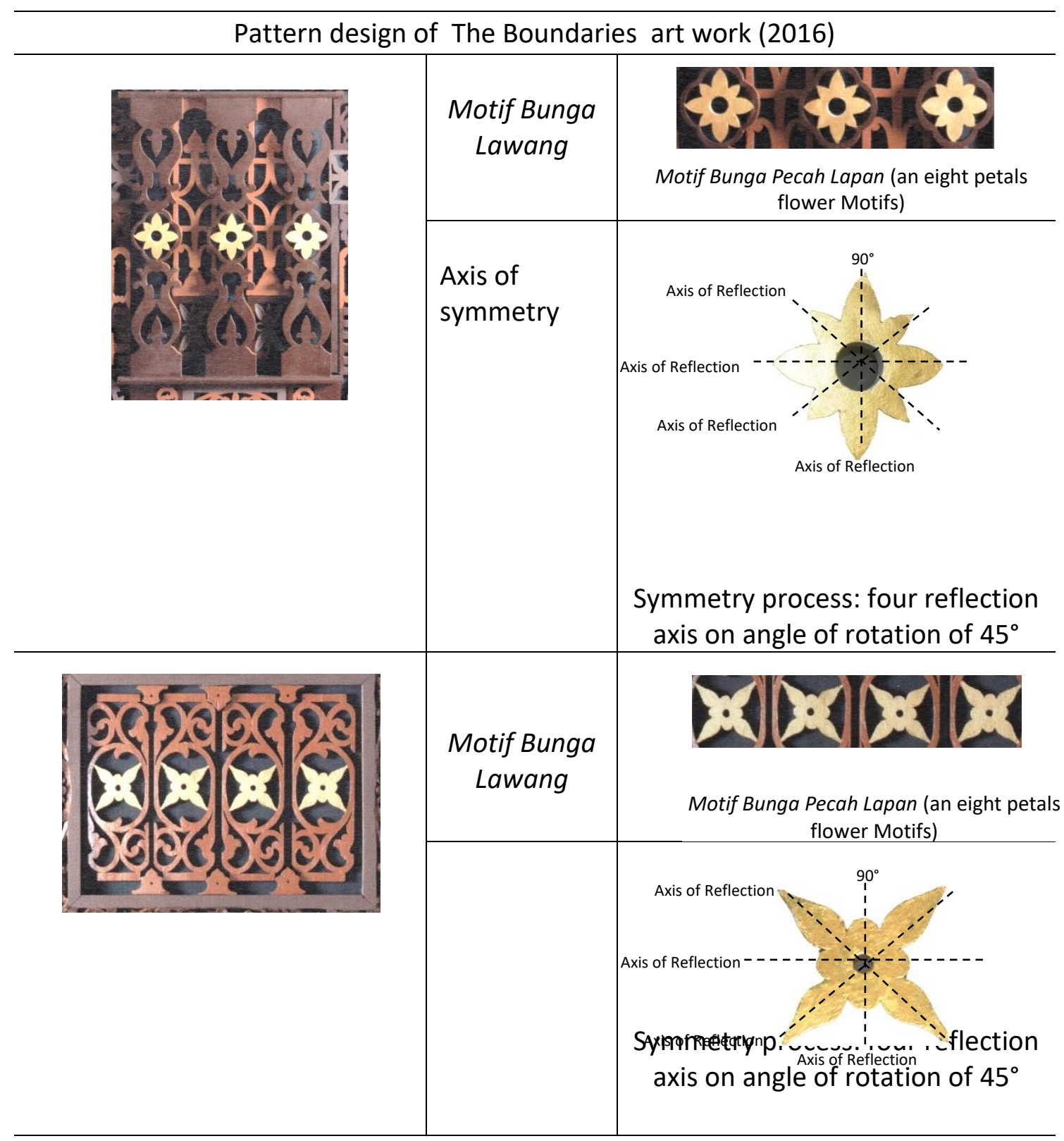

The table above shows the motifs of these plants being manipulated and modified into interesting variations. Examples of flora motifs used are Bunga Pecah Lapan Motif which displays eight petal flowers from the top view which is Bunga Lawang which is inspired by spices (Rashid, 2009). This herb belongs to the spices and looks like a four -symmetrical starshaped (Ong, 2008). It has eight petals or a radial shape and the middle part is dark brown. These motifs can be broken down into specific parts and patterns can be varied. 
Meanwhile, the table also shows the concept of symmetry of the four axes of reflection that produce eight angles of rotation valued at $45^{\circ}$ each. It is to form a pattern that has a diagonal balance through symmetrical balance. The design of the arrangement for these motifs in the artwork is horizontal.

Table 2. Geometric design and symmetry of motifs by The Boundaries art work.

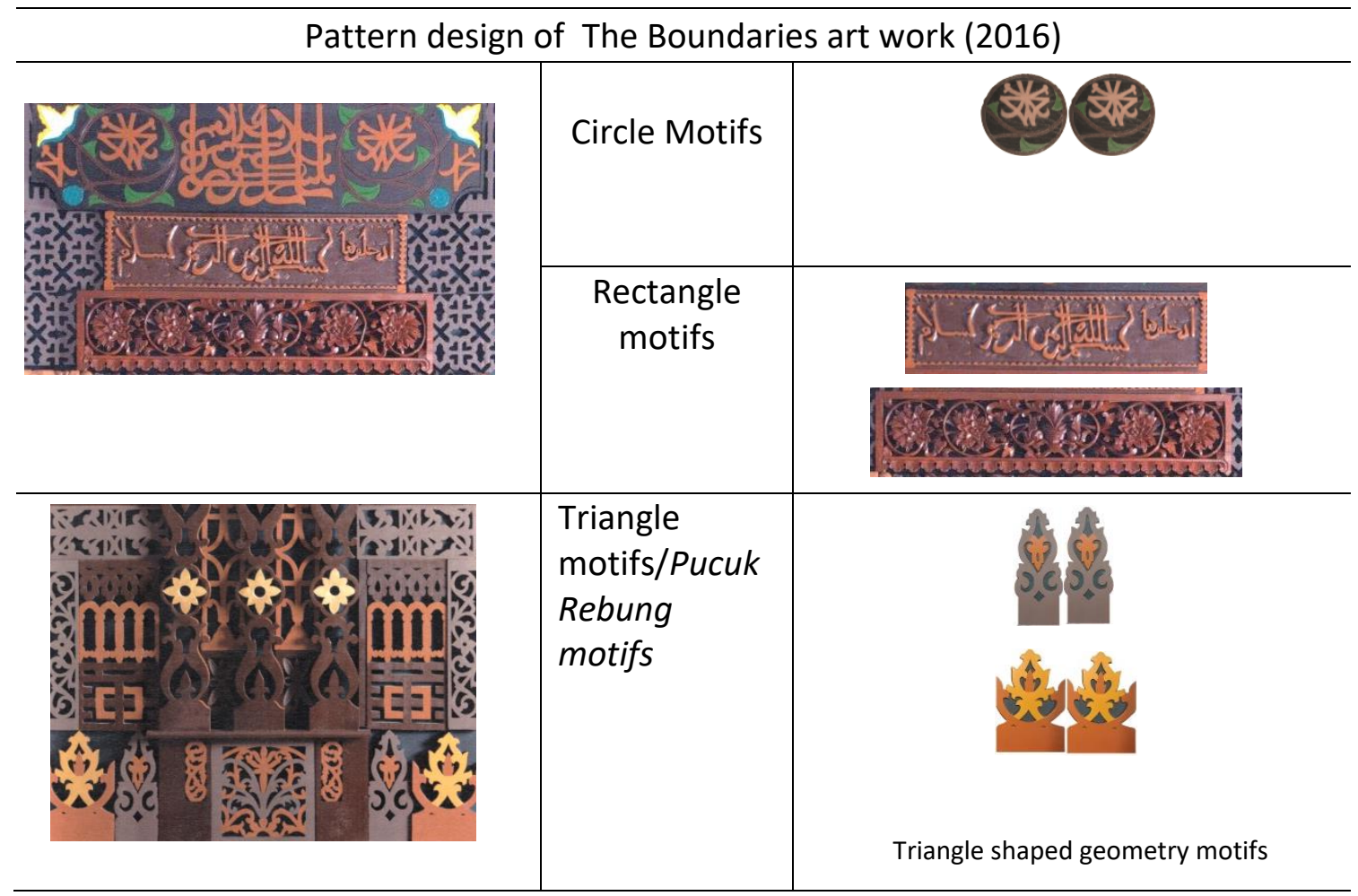

The table above displays the circle motif as a sequential pattern design in the artwork. A circle is a set of points that are equidistant from a fixed point. The center of the circle is equal to the center of circumference. It allows joining the center with any perimeter point. The size of the circle motif is fixed in shape and has no significant differences showing a parallel and continuous line of motif arrangement in the artwork.

A rectangular motif is a rectangle that has two pairs of opposite sides that are equal in length and four corners that are all right angles. The longest side is known as the length and the shortest is known as the width. It can be seen in the artwork above.

The table above also displays the motif of pucuk rebung (rebung) which is a motif in the category of geometry that represents the universe/mountain in the form of a triangle. The motif in rebung pucuk (rebung) expresses the beauty of the universe because its origin is from 'something beautiful' (referring to the Divine Reality). The 'universe' is described in a triangle that is divided into four areas, namely Alam Syahadah (universe), Alam Mithali (the supernatural realm), the Alam Arwah (spiritual world) and Zat Allah. Similarly, the motif mentioned is known as the 'mountain' motif. (Mohamad, 1984). Traditional motifs include a combination of floral, cosmic and geometric motifs that convey symbolic meaning. 
Table 3. Geometric design and symmetry of motifs by The Boundaries art work.

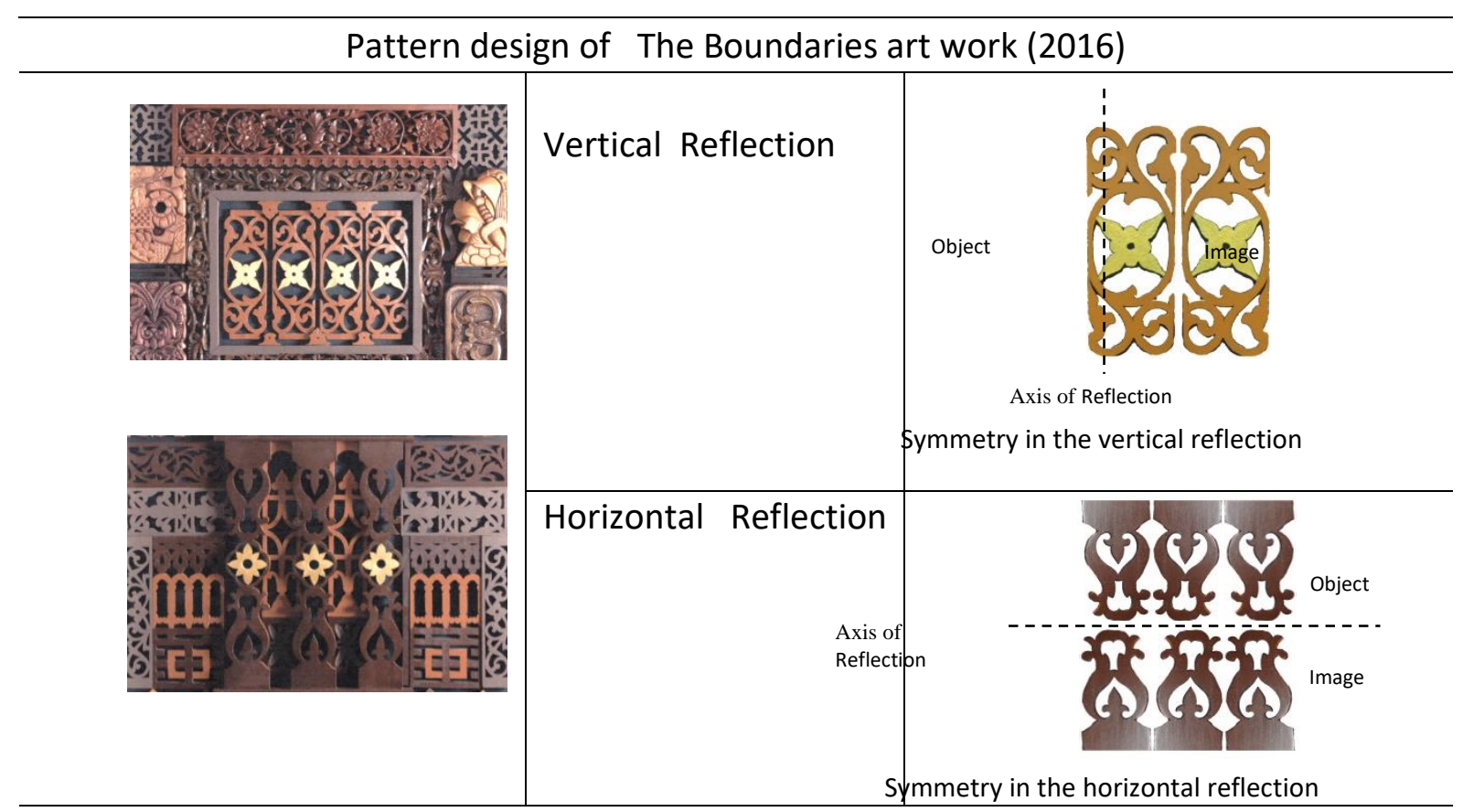

The table above shows that reflection is a type of transformation that basically reverses all the natural points of a plane on a line called the axis of reflection. Objects from the image have the same shape and size as the inverted image orientation. The points on the reflection axis are unchanged. Therefore, the invariant point for this type of transformation is infinite. Each point on the object and the distance of the image that has been reflected has the same distance from the axis of reflection. In other words, the axis of reflection lies midway between the object and the image (Ronning, 2009).

The table also describes the concept of symmetry which is about the process of image repetition through vertical and horizontal reflection. The motif (object) is reflected on the reflection axis and produces the motif (image) in reverse without changing the original shape.

\section{Analysis of Symmetry Elements in Artwork}

Frieze patterns are repeating patterns formed by symmetry in one direction. The symmetries' are translation, rotation, reflection or gliding reflection. According to Umble (2014) frieze group is a group in a symmetrical pattern. Joseph A.Gallian (1998) stated that the formation of symmetrical group's structure in frieze is classified into seven types of friezes pattern. The system to divide this symmetric group is by using number and key code scheme to classify this frieze pattern as attached below: 
Table 4. Four types of methods to produce symmetrical patterns

\begin{tabular}{|c|c|c|c|c|}
\hline \multicolumn{5}{|c|}{ FRIEZE PATTERN } \\
\hline No & Type & Description & First code & Second code \\
\hline 1. & $\begin{array}{l}\text { Translatio } \\
\mathrm{n}\end{array}$ & $\begin{array}{l}\text { Repeating motifs } \\
\text { slides up or down } \\
\text { either vertical, } \\
\text { horizontal or } \\
\text { diagonal }\end{array}$ & $\begin{array}{r}1=\text { no vertical } \\
\text { symmetry }\end{array}$ & $\begin{array}{l}\begin{array}{l}1=\text { no } \\
\text { additional } \\
\quad \text { symmetry }\end{array}\end{array}$ \\
\hline 2. & Rotation & 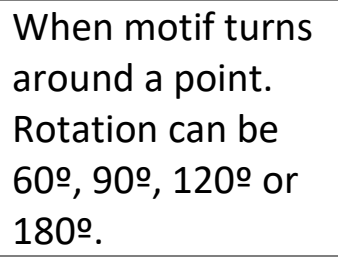 & & $\begin{aligned} 2= & \text { half turn } \\
& \text { symmetry }\end{aligned}$ \\
\hline 3. & Reflection & $\begin{array}{l}\text { When motif } \\
\text { reflects and the } \\
\text { image reverses as } \\
\text { in a mirror }\end{array}$ & $\begin{array}{l}\mathrm{m}=\text { vertical } \\
\text { reflection } / \\
\text { cross line } \\
\text { symmetry }\end{array}$ & $\begin{array}{c}\mathrm{m}=\text { horizontal } / \\
\text { midline } \\
\text { symmetry }\end{array}$ \\
\hline 4. & $\begin{array}{l}\text { Glide } \\
\text { reflection }\end{array}$ & $\begin{array}{l}\text { When motif } \\
\text { translates along } \\
\text { the axis and at the } \\
\text { same time reflects } \\
\text { across an axis. }\end{array}$ & & $\begin{array}{l}\mathrm{g}=\text { glide } \\
\text { reflection } \\
\quad \text { symmetry }\end{array}$ \\
\hline
\end{tabular}

Table 5. Analyze pattern designs that are classified through seven frieze patterns

\begin{tabular}{|c|c|c|c|}
\hline No. & $\begin{array}{l}\text { Symmetry } \\
\text { group }\end{array}$ & Description & Illustration \\
\hline 1. & $\mathrm{Pmm} 2 / 11$ & translation & $\mathrm{bbbbbbbb}$ \\
\hline 2. & $\mathrm{P} 112 / 12$ & Translation and rotation & $b q b q b q b q$ \\
\hline 3. & P1a1/1g & Translation and vertical reflection & $b p b p b p b p$ \\
\hline 4. & $\mathrm{Pm} 11 / \mathrm{m} 1$ & Translation and horizontal reflection & $b d b d b d b d$ \\
\hline 5. & $\mathrm{P} 1 \mathrm{~m} 1 / 1 \mathrm{~m}$ & Translation and glide reflection & $\begin{array}{l}\text { b b b b b b b b } \\
n n n n n n n n\end{array}$ \\
\hline 6. & $\mathrm{Pmm} 2 / \mathrm{mm}$ & $\begin{array}{l}\text { Translation, glide reflection and vertical } \\
\text { rofloction }\end{array}$ & $\begin{array}{l}n n n n n n n n \\
b d b d b d b d \\
n a n n n a n n a\end{array}$ \\
\hline 7. & $\mathrm{Pma2} / \mathrm{mg}$ & Horizontal reflection, vertical reflection, & bqpdbqpd \\
\hline
\end{tabular}


Table 6. Analyse model friezes table

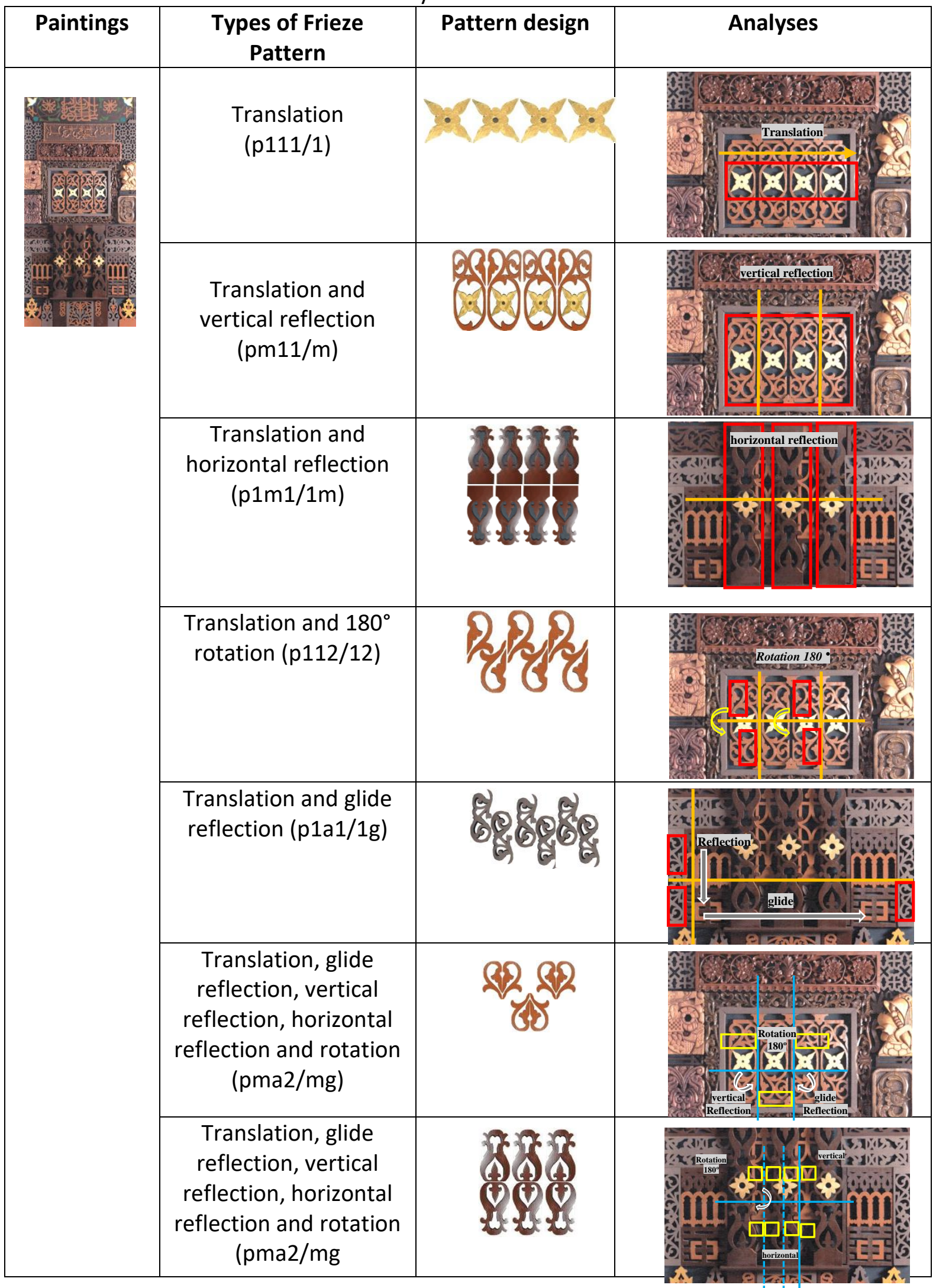

\section{Conclusion}

The results show the importance of geometric design in the production of meaningful and aesthetically valuable artworks. This study contributes to the understanding of the meaning 
of concept and purpose of the design geometry to be applied in the form of images and paintings featured Malay Muslim identity. Artworks are produced in the context of the structure of form and elements where the use of elements of variation, repetition, image reflection and colour effects in creating artworks that are capable of influencing and changing perceptions and emotions. The elaboration of variation elements through a repetitive geometric system of shape and form. The entire content of the artwork contains aesthetics that create the value of beauty.

From the findings through the work of paintings that was studied has the structure of the principle of symmetry in each elaboration which is based on the calculation of symmetry that exists in the field of mathematics. The contribution of new information can encourage the community to appreciate the beauty of artworks of art from different perspectives in terms of the beauty of the concept and the value of symmetry. It can be seen in the motifs and patterns that exist in paintings. The study focused on the aspects of Malay and Islamic symbols. Through these identities, this study elevates the art of painting in Malaysia by maintaining the local culture as a reference to produce artworks related to traditional culture. The existence of artworks which follow Malays and Islamic cultural in paintings can provide development and design patterns that still maintain traditional and Islamic values.

\section{Acknowledgement}

Alhamdulillah, all praises to Allah for the strengths and His blessing in completing this thesis. Special appreciation goes to family, my daughters and my husband, for his supervision and constant support. His invaluable help of constructive comments and suggestions throughout the research have contributed to the success of this article journal.

\section{Corresponding Author}

Rushana Sulaiman @ Abd Rahim

Senior Lecturer Fine Art Department, Faculty of Art and Design, Universiti Teknologi Mara, Kampus Machang, Kelantan, Malaysia

Email: rushana@uitm.edu.my

\section{Reference}

\section{Book}

Bakar, O.(1995).Memahami Konsep Memanifestasikan Islam Dalam Kesenian Islam: Suatu Perspektif Malaysia. Balai Seni Lukis Negara. Kuala Lumpur.

Basaree, R. O. (2018).Simbiosis Keharmonian Seni Tradisional dan Seni Digital Kontemporari.Balai Seni Visual Negara. Kuala Lumpur.

Gallian, J. (1998). Contemporary Abstract Algebra.Boston: Houghton Mifflin.

Ismail, M. R. (2004).Etnomatematik. Matematik Merentas Tamadun. Falsafah Pengajian Sejarah Matematik. Kuala Lumpur: Dewan Bahasa Dan Pustaka.

Mohamad, A. (1984). Falsafah dan Pemikiran Orang-orang Melayu: Hubungannya Dengan Islam dan Kesenian. Kuala Lumpur: Kementerian Kebudayaan, Belia dan Sukan.

Ronning, F. (2009).Islamic patterns and symmetry groups.Sor-Trondelag University College.Norway.

Umble, R. N. (2015).Transformational Plane Geometry.Chapman and Hall/CRC. 


\section{Thesis}

Kamal, M. (2016). Kritikan seni dari perspektif sosio budaya Malaysia. Universiti Malaya. Kuala Lumpur.

\section{Journal}

Martin, G. E.(1982).Transformation Geometry An Introduction to Symmetry. Springer New York.

Nawawi, N. M. ( 2014). Innovation of Corn Husk Fiber into Songket Weaving Towards Sustainability of Cottage Industry. i-CADER.International Colloquium of Art \& Design Education Research.

Umble, R. N., \& Han, Z. (2014). Transformational plane geometry. Transformational Plane Geometry. https://doi.org/10.1201/b17787

Washburn, D. K. (1988). Analysis of Pattern Structure by Geometric Symmetries .Textile Society of America Symposium Proceedings. 649.

Weyl, H. (1952) Symmetry.Princeton University Press, 1952 - Mathematics - 168 pages.

Yusoff, Z. M. (2016).The Ornamental Design of Traditional Malay Utensils (Kukuran ) in Peninsula Malaysia. SHS Web of Conferences.

\section{Newspaper}

Abdullah, A. H. (2015). Merangsang Pemikiran Geometri Pelajar. Berita Harian. 